\title{
Clinical judgment and harmonic ultrasonography in the diagnosis of acute appendicitis: Experience with a modified score-aided diagnosis.
}

\author{
Ossama M Zakaria,a MD; Tamer A Sultan,b MD
}

a) Division of Pediatric Surgery, Department of Surgery, Suez Canal University, Egypt.

b) Division of Pediatric Surgery, Department of Surgery, Menoufyia University, Egypt.

Co"espondence: e-mail: ossamaz2004@yahoo.com

\begin{abstract}
Background: Appendicitis is the most common surgical emergency in children, yet diagnosis of equivocal presentations continues to challenge clinicians.

Aim: The objective of this study was to investigate the hypothesis that the use of a modified clinical practice and harmonic ultrasonographic grading scores (MCPGS) may improve the accuracy in diagnosing acute appendicitis in the pediatric population.

Patients \& methods: Main outcome measures: Sensitivity, specificity, and accuracy ofthe modified scoring system. Five hundred and thirty patients presented with suspected diagnosis of acute appendicitis during the period from December 2000 to December 2009 were enrolled in this study. They were classified into 2 equal groups.

Group I ( $n=265)$ : Included children who presented with suspected diagnosis of acute appendicitis. To these children a special clinical practice guideline system (CPGS) incorporating clinical judgment and results of gray scale US was applied), 2

Group II (n=265): Included a similar group of children with equivocal diagnosis of acute appendicitis (AA), to whom a modified clinical practice guideline system (MCPGS) was applied.

Statistical analyses were carried out using $Z$ test for comparing 2 sample proportions and student's t-test to compare the two quantitative data in both groups. Sensitivity and specificity for the 2 scoring systems were calculated using Epi-Info software.

Results: The Number of appendectomies declined from 200 (75.5\%) in group I to $187(70.6 \%)$ in group II $(P>0.05)$.

Specificity was significantly higher when applying MCPGS (90.69\%) in group II compared to $70.47 \%$ in group I when CPGS was applied $(P<0.01)$. Furthermore, the PPV was significantly higher in group II $(95.72 \%)$ than in group I $(82.88 \%)(P<0.01)$.

Conclusions: MCPGS tends to reduce the numbers of avoidable and unnecessary appendectomies in suspected cases of pediatric acute appendicitis that may help in saving hospital resources.

Key words: Acute appendicitis, children, Harmonic ultrasound scan, CPGS, MCPGS.
\end{abstract}




\section{Introduction:}

Certainty of clinical diagnosis is the most challenging task in clinical practice. It is relatively straight forward to look up the treatment once a correct diagnosis has been made. A single perfect diagnostic test for acute appendicitis does not exist.1,3

Despite the number of algorithms and diagnostic tests available, about 200/o of patients with appendicitis are misdiagnosed.3-9

Presence of normal appendix ranges from $5-25 \%$ out of suspected cases of acute appendicitis.5,10-13 Negative appendectomies were thought to be relatively harmless; nevertheless, they result in considerable unnecessary clinical and economic costs.t4 Even despite the uncertainty of diagnosis, appendicitis demands prompt treatment in order not to be neglected and misdiagnosed leading to progression of the disease with its associated morbidity and mortality that may include the risk of perforation which happens in approximately one third of the cases.5, 15,16

Inan attempt to improve diagnosis, attention has turned to radiological imaging. The use of ultrasound scan (US) has been advocated as the readily available simple and fast imaging modality particularly in thin patients and children. A normal appendix is not frequently observed using gray-scale US, 17-18 however, on the other hand, Harmonic imaging (HI) increases the contrast and spatial resolution resulting in artifact-free images, and has been shown to significantly improve abdominal ultrasonography. However, only a handful of reports exist regarding its application in pediatric patients. Most of them do not encompass its use in acute appendicities.t9 This work aimed to investigate and assess the hypothesis that the use of a modified clinical practice, judgment and harmonic ultrasonography as a modified score-aided diagnosis; MCPGS may improve the accuracy in diagnosing acute appendicitis in children with equivocal pictures of acute appendicitis and to compare these results with those of previously published data of CPGS), 2

\section{Patients and methods:}

The study was carried out during the period from December 2000 to December 2009. Cases of suspected pediatric acute appendicitis were included in the study. The first 265 cases were referred to as Groupl to whom the clinical judgment and ultraosongraphy score aided CGPS was applied. ${ }^{1}$ This was a modification of previously published scoring methods 2,3 including certain subjective clinical parameters measured as 1 point such as fever of 38, anorexia and vomiting, tachycardia of more than 120 beats/minute. Abdominal pain parameters were also measured with special emphasis on guarding or rigidity, positive perrectal examinations, however, a positive rebound tenderness was given 3 points in this score method as well as other clinical, laboratory and harmonic US measurements Table(l); Results for this group are already published. I The next 265 cases were referred to as Groupll to whom the proposed usage of harmonic ultrasonography clinical judgment and practice as a modified score aided system MCPGS was applied.

Groupll ( $n=265)$ : consisted of a similar group of children in whom our modified score aided system MCPGS with twenty five variables including harmonic ultrasound (US) examination and a marker of inflammatory response was assessed in multivariate analysis using the finding of AA at operation as the end point were enrolled in this study Table(2). Exclusion criteria included those who were proved to have other causes of acute abdominal pain rather than acute appendicitis. Children were equally distributed regarding sex and age into 2 equal groups.

illtrasonography was performed using linear and curved transducers with ultrasound frequencies ranging between 2.5 and $7.5 \mathrm{MHz}$, commercially available US systems (Sonoace XP8; Medison, Korea). The examination was performed with both conventional and harmonic imaging US. Scanning parameters were optimized for each method, and all images were obtained with the use of the same focal zone. An external video with cine playback mode was used to obtain identical images in two standard planes, longitudinal and transverse scans. Images were obtained with the two methods in random sequence to facilitate their masking for the observers. Harmonic images were acquired at a transmitting frequency of 
2.0 $\mathrm{MHz}$ and a receiving hannonic bandwidth of $4.0 \mathrm{MHz}$. Conventional US images were obtained at a frequency of $3.5 \mathrm{MHz}$, which is a frequency used commonly at abdominal imaging in adults. The harmonic and conventional US modes were switched by means of a toggle switch on1he scanner control panel Figure(l). In both groups the rationale of active watchful waiting in suspected appendicitis was a prudent and safe strategy with the use of at least one time repetition of conventional US or Harmonic US in groups I and $\mathrm{n}$, respectively with no increase in the risk of perforation.

All appendices were routinely sent for histopathological examination.

Collected data were statistically analyzed using X2 test. Continuous variables were analyzed using $\mathrm{Z}$ test and student's t-test.

.05 were considered statistically significant Sensitivity and specificity were calculated for the CPGS. Kappa test was used to verify the specificity. All calculations were performed using SAS version 8.2.

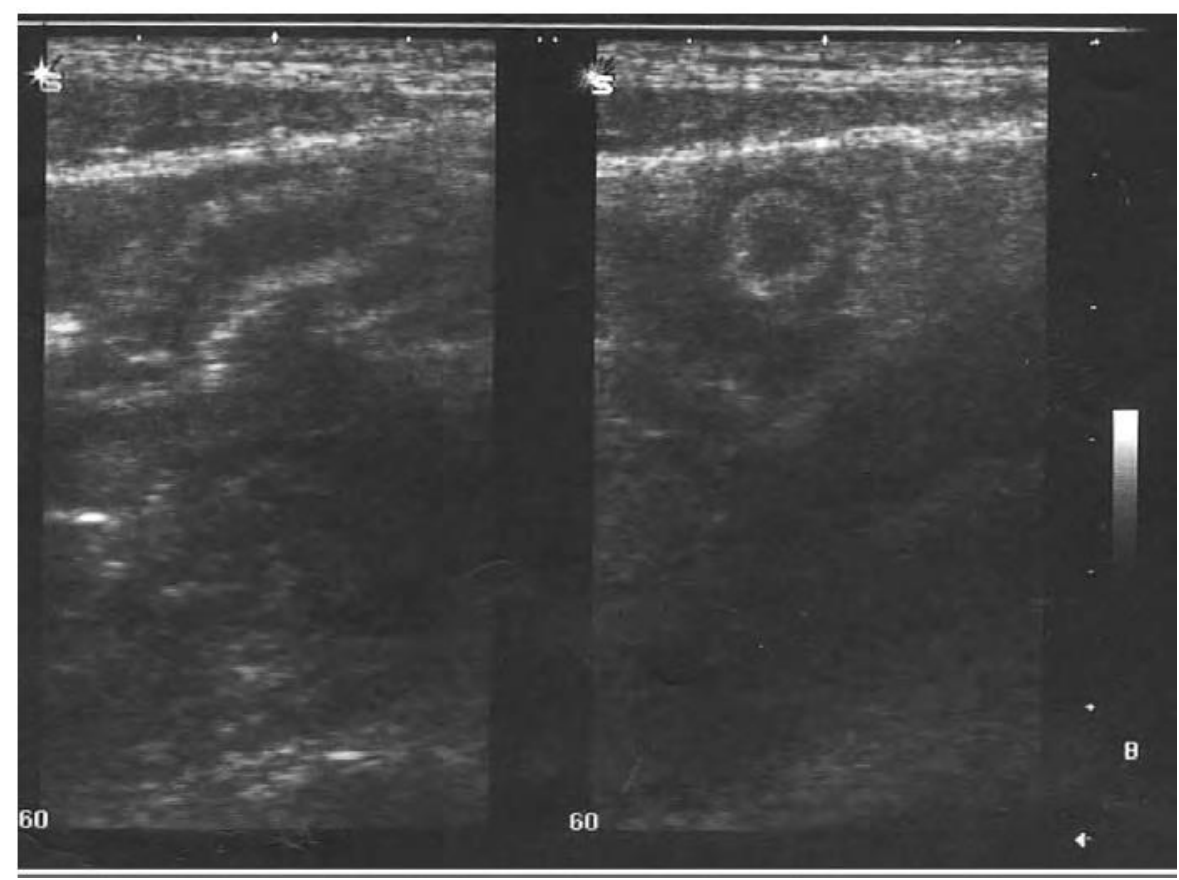

(A)

(B)

Figure (1): Acute appendicitis by conventional US

(A) Longitudinal scan showing a peristaltic non compressible blind ended tubular structure with distinct thickened wall/ayers and diameter $>6 \mathrm{~mm}$

(B) Transverse scan showing target sign appearance. 
Table (1): Clinical Practice Guideline Scoring System (CPGS) 1.

\begin{tabular}{|c|c|c|c|c|c|}
\hline & & & & & \\
\hline & & & 1 & 0 & Score \\
\hline Clinical data & General & -Fever & Yes & No & \\
\hline & & $-\mathrm{HR}$ & $>120 / \mathrm{min}$. & $<120 / \mathrm{min}$. & \\
\hline & & -Vomiting & Yes & No & \\
\hline & & - Dehydration & Yes & No & \\
\hline & Abdominal & Abd.pain & & & \\
\hline & & -Localized & Yes & No & \\
\hline & & $\begin{array}{l}\text {-History of } \\
\text { similar - attacks }\end{array}$ & No & Yes & \\
\hline & & -Character & Constant & Intermittent & \\
\hline & & -Severity & Intolerable & Tolerable & \\
\hline & & -Course & Progressive & Regressive & \\
\hline & & $\begin{array}{l}\text { - Reliefby } \\
\text { antispasmodic }\end{array}$ & No & Yes & \\
\hline & & $\begin{array}{l}\text { - Bowel Habit } \\
\text { alteration }\end{array}$ & Yes & No & \\
\hline & & $\begin{array}{l}\text {-Rebound } \\
\text { tenderness }\end{array}$ & Yes (3) & No & \\
\hline & & $\begin{array}{l}\text { - Guarding or } \\
\text { rigidity }\end{array}$ & Yes & No & \\
\hline & & $\begin{array}{l}\text { - +veP.R. } \\
\text { examination }\end{array}$ & Yes & No & \\
\hline Investigations & Laboratory & -WBCs & Yes & No & \\
\hline & & leukocytosis & & & \\
\hline & & $\begin{array}{l}\text { - Urine analysis } \\
\text { (Findings ofUTI) }\end{array}$ & Yes & No & \\
\hline & $\begin{array}{c}\text { Focused } \\
\text { abdominal }\end{array}$ & $\begin{array}{l}\text { - Appendicitis } \\
\text { or mass }\end{array}$ & Yes & No & \\
\hline & U.S. & $\begin{array}{l}-+ \text { ve fmdings in } \\
\text { female Adnxae }\end{array}$ & No & Yes & \\
\hline & & $\begin{array}{l}-+ \text { ve fmdings in } \\
\text { liver, Gall } \\
\text { bladder, } \\
\text { billiary passages }\end{array}$ & No & Yes & \\
\hline & & $\begin{array}{l}\text { - +ve fmdings } \\
\text { kidneys }\end{array}$ & No & Yes & \\
\hline & & -Free fluid & Yes & No & \\
\hline tal sce & & & & & \\
\hline
\end{tabular}

Interpretation of results:

21 - 15 =Highly suggestive of appendicitis.

14- $8=$ Patient needs repeated evaluation for conclusive result.

7- $0=$ The diagnosis of acute appendicitis in not likely. 
Table (2):Modified clinical practice and harmonic ultrasonographic grading score (MCPGS).

Clinical data General -Fever

Abdominal -HR.

-Vomiting

Abd.pain

-Localized

- History of similar - attacks

-Character

-Severity

-Course

-Relief by antispasmodic

- Bowel Habit alteration

Laboratory

-tenderness

- Guarding or rigidity

Focused

-+ve P.R.

Investigations abdominal Associated intra- abdomin.. Disease No

U.S.

-High WBCs

- Elevated CRP

-Urine analysis (Findings ofUTI)

-Aperistaltic non- Compressible

blind ended tubular structure

-Distinct thickened appendicial

wall layers

- Outer diameter> $6 \mathrm{~mm}$

-Target sign appearance

Total score

-Appendicolith(s)
$1 \quad 0$

Yes

$>120 /$ min. $<120 /$ min

Yes

No

Yes

No

No

Yes

Constant Intermittent

Intolerable Tolerable

Progressive Regressive

No Yes

Yes

No

Yes

No

Yes

Yes

No

No

Yes

No

No

Yes

No

Yes

Yes

No

-Periappendiceal

Yes

No

Yes

No

fluid collection

-Echogenic Prominent pericecal fat Yes

No

-+ ve fmdings in female

Adnexae

No

Yes
Score 
Table (3): Sensitivity, specificity, PPV and NPV for Group IL

\begin{tabular}{|l|c|c|c|}
\hline \multirow{2}{*}{ MCPGS } & \multicolumn{2}{|c|}{ Histopathology } & \multirow{2}{*}{ Total } \\
\cline { 2 - 3 } & $+\mathrm{ve}$ & $-\mathrm{ve}$ & \\
\hline$+\mathrm{ve}$ & 179 & 8 & 187 \\
\hline$-\mathrm{ve}$ & 0 & 78 & 78 \\
\hline Total & 179 & 86 & 265 \\
\hline
\end{tabular}

Sensitivity $=100 \%$

PPV $=95.72 \%$
Specificity $=90.69 \%$

$\mathrm{NPV}=100 \%$

The Number of appendectomies declined from 200 (75.5\%) ingroup I to 187 (70.6\%) in group II $(\mathrm{P}>0.05)$.

\section{Results:}

Our study included 530 children of whom 280 were males and 250 were females, with a male to female ratio of 1.12:1. Our patients aged between one year and 17 with a mean age of $12.6 \pm 1.4$ (mean \pm S.D.). No significant differences were observed between the two groups as regard age and sex distribution.

In group I, traditional clinical judgment and grey scale US score aided CPGS were performed. 200 patients $(75.5 \%)$ underwent appendectomy, of them 35 appendices (17.5\%) were normal at histopathological evaluation. The remaining 65 patients $(24.5 \%)$ were discharged from the Pediatric Surgical Facility as not having appendicitis. Yet, out of those 65,3 children $(4.6 \%)$, ( 2 males and I female) were re-admitted. Ultrasonography was repeated suggesting acute appendicitis. They underwent appendectomy with positive pathological results. A total of 203 appendectomies (76.6) were performed in this group.

In group II, I87 patients $(70.6 \%)$ have undergone appendectomy, of them 90 patients (48.1\%) showed an MCPGS score between I5 and 22, those patients were kept with no oral feeding (NPO), intravenous fluid infusion (IV fluid) of appropriate type and amount according to patient's age before undergoing appendectomy.

Only 8 out of the total appendectomies $(4.3 \%)$ were normal at histopathological evaluation.

The remaining 97 patients (36.6\%) initially showed MCPGS of 8-I4. On repeated evaluation every 2 hours for a maximum of 6 times and repetition of harmonic US during the repeated evaluation for at least one time, their score progressed to 15 or more [61 patients $(62.9 \%)$ with a MCPGS of I5-I7, II patients (Il.3\%) with MCPGS of 18, and 25 patients (25.8\%) with MCPGS of I9]. During the observation period, these patients were kept with nothing to be taken orally (NPO), intravenous (IV) fluids were administered as appropriate. No antibiotics were given in order not to alter the clinical picture. However, antibiotics were started once the diagnosis was confirmed. No false negative cases were recorded when using MCPGS.

On the other hand, 78 children $(29.4 \%)$ did not undergo appendectomy, 48 of them $(61.5 \%)$ showed MCPGS of 8 or less at the initial examination. They were referred to the Pediatric Medical Care with no need for surgical interventions. Thirty patients $(38.5 \%)$ showed MCPGS between 9 and 14 declining with repeated examinations until their score became definitely 8 or less, they were managed medically.

Specificity ofMCPGS was higher than that of CPGS, this may be attributed to the use of harmonic US in this modified scoring system that seems to be significantly superior to the conventional grey scale US $90.69 \%$ in group! Table(3) compared to a specificity of $70.47 \%$ in group II $(\mathrm{Z}=5.999, \mathrm{P}<\mathrm{O} . \mathrm{OI})$. Also the Positive Predictive Value for group II (95.72\%) was significantly higher than that of group! $(\mathrm{Z}=4.727, \mathrm{P}<\mathrm{O} . \mathrm{OI})$. Applying Kappa analysis on that data of Table(1) revealed the Kappa Measure for Agreement to be 0.929 (93\%), Confidence intervals (88.I-97.7), 
(MCPGS vs. Histopathology), Z Kappa $=15.1$, P value ofO.OOOl. These results show the high specificity of our fmding in the MCPGS group.

\section{Discussion:}

Acute appendicitis traditionally has been a clinical diagnosis and remains so to this day. The diagnosis can be difficult to make in many children who may present with atypical symptoms or an equivocal physical examination. ${ }^{18}$

In our current study, the newly advocated score aided guideline system (MCPGS) based on clinical judgment, laboratory investigations for inflammatory response and harmonic US studies (Hn in association with the strategy of active watchful waiting performing repeated clinical examinations as well as at least one time repetition of Harmonic US before the decision-making process. It was highly accurate in the diagnosis of acute appendicitis in children. The specificity of the MCPGS was $90.69 \%$ compared to a specificity of $70.47 \%$ in the children to whom CPGS and active watchful waiting strategy was applied. In addition, we observed a statistically significant decrease in the negative appendectomy rate in groupll compared with those in groupl. The decrease in negative appendectomies occurred without a rise in the perforation rate. In fact, the perforation rate was lower under the MCPGS, although this change was not significant.

The inclusion and exclusion criteria of group formation in our study aimed at avoiding any selection bias as regards the patient's age and sex, attending hospital staff, investigatory facilities whether laboratory or radiological and the pediatric surgical team. Our study aimed at avoiding the selection bias mentioned before in similar scoring system.19 Screening ultrasound scanning for pediatric appendicitis has suboptimal accuracy, particularly in obese children with a low likelihood of appendicitis who should not routinely undergo ultrasound scanning. However, when followed by a second ultrasound scanning or a clinical reassessment, it offers high diagnostic accuracy in lean children. ${ }^{2} 0$

Targeted abdominal examination as well as hannonic ultrasound scan $\mathrm{HI}$ constituted around
$75 \%$ of our MCPGS scoring system with the aim of increasing its specificity without affecting the system sensitivity.

Results showed the superiority ofharmonic imaging over conventional US for lesion visibility, with harmonic imaging being preferred over conventional US for $65 \%$ of cases. The fmdings were clearer and better defmed with harmonic imaging which thereby improved the detection of subtle lesions. Harmonic imaging theoretically improved signal-to-noise ratios by reducing noise from side lobe artifact in the near field and echo detection from multiple scattering events.

This reduced noise was most likely responsible for the superiority of harmonic imaging over conventional US in the visualization of the findings and improved the confidence of diagnosis for most cases. Harmonic imaging was superior to conventional US in the visualization of lesions containing highly reflective tissues such as fat, calcium and air. It is therefore recommended to be used in obese patients. Better definition of the posterior acoustic shadows in calcifications and appendicolith(s).21-28

In our study the negative appendectomy rate in groups I and II was 17.5 and $4.3 \%$, respectively. Contrary to our results of group I some did show a negative appendectomy rate of $5.5 \%$ by applying somewhat similar scoring system. 19 The reason for such difference may be their use of CT scanning in their system. However, the difference in the negative appendectomy rate does not support the use of such an expensive sophisticated and hazardous radiological tool to children. CT scanning is not always available in all centers limiting its incorporation in clinical practice guideline scoring system. A recently published study of a practice guideline found that CT scan did not improve the accuracy of diagnosis in patients with suspected appenecistis.29 Their guideline did not specifically address the appropriate use of CT scan. Our study results ofMCPGS, however, did show a great decline in the rate of negative appendectomies. This goes with data of some authors who showed that an imaging protocol using US followed by $\mathrm{CT}$ in their patients with equivocal presentations improved the accuracy of 
diagnosis of appendicitis.30 We present our current results ofMCPGS which evolved from this and other studies recommending ultrasound as the imaging modality of choice in most patients. In addition the recommendation of MCPGS was not limited to imaging alone. Most clinical practice guidelines encourage, but do not require complaints with recommendations)!Measuring complaints can be challenging because guidelines can include numerous recommendations and because patients do not, especially children do not always match preconceived scenarios 32 Although many barriers limit physician acceptance of guidelines, 33the compliance with our MCPGS is consistent with other developed practice guidelines.2,3,6-9,34 A considerable portion of the improvement seen in our study could be because of the utilization and accuracy of suitable imaging. Practice guidelines and clinical pathways have been implemented for many conditions, 26 including acute appendecitis)6,30,35 Analysis of such guidelines can focus on any combination of patient outcome, resource utilization or complaints with recommendation.16,34-36

Although most appendicitis guideline and pathways focus on decreasing postoperative treatment cost, a few concentrate on diagnosis itself. One such pathway in a pediatric hospital achieved a significant reduction in the number oflaboratory tests and X-rays without adversely affecting the incidence of negative appendectomies or perforation.34 However, in our proposed MCPGS we included the minimum necessary laboratory investigations to measure the inflammatory response and time and effort saving harmonic abdominal ultrasound scan in order to decrease the probabilities of misdiagnosing acute abdominal pain due to other reasons as acute appendicitis.

In our current study both groups underwent the active watchful waiting strategy. This excludes that the decision-making process did result strictly from the MCPGS scale, and was not rather based on the repeated clinical reevaluation that was adopted also on PGCS. This exactly shows that our proposed score is superior to the real life common clinical practice.
It may be concluded that the use of a modified clinical and harmonic ultrasonographic grading score (MCPGS) with the rationale of active watchful waiting in suspected appendicitis with at least one time repetition of Harmonic US was a prudent and safe strategy. It may improve the accuracy of diagnosing acute appendicitis in the pediatric population as it is superior to the real life common clinical practice. It leads to fewer negative appendectomies compared with those children to whom it was not applied or other scoring systems were applied as the CPGS with the same strategy of active watchful waiting and repeated US, without a significant change in the perforation rate. Moreover, inpatient observation for serial examinations was reduced significantly. Guidelines such as this can have considerable impact on the diagnosis of acute appendicitis in children. A larger cohort is necessary to validate our findings.

\section{References:}

1- Zakaria OM, Adly OA, El-Labban GA, Khalil HT: Acute appendicitis in children: A clinical practice guideline scoring system. Suez Canal Univ Med J2005; 8: 20-26.

2- Fran ois Y, Bonvoisin S, Descos L, Vignal J: Prospective study of a predictive scoring system for the diagnosis of appendicitis in patients with right lower quadrant pain. Long-term outcome. Gastroenterol Clin Bio/1991; 15: 794-799.

3- Samuel M: Pediatric appendicitis score. J Pediatr Surg 2002; 37: 877-881.

4- Rezak A, Abbas HM, Ajemian MS, Dudrick SJ, Kwasnik EM: Decreased use of computed tomography with a modified clinical scoring system in diagnosis of pediatric acute appendicitis. Arch Surg 2011; 146: 64-67.

5- Dado G, Anania G, Baccarani U, Marcotti E, Donini A, Risaliti A, Pasqualucci A, Bresadola F: Application of a clinical score for the diagnosis of acute appendicitis in childhood: A retrospective analysis of 197 patients. JPediatr Surg 2000; 35: 13201322.

6- Escriba A, Gamell AM, Fernandez Y, 
Quintilla JM, Cubells CL: Prospective validation of two systems of classification for the diagnosis of acute appendicitis. Pediatr Emerg Care 2011; 27:165-169.

7- Shera AH, Nizami FA, Malik AA, Naikoo ZA, Wani MA:Clinical scoring system for diagnosis of acute appendicitis in children. Indianjoumal of pediatrics 2011; 78: 287 290.

8- Shreef KS, Waly AH, Abd-Elrahman S, Abd Elhafez MA: Alvarado score as an admission criterion in children with pain in right iliac fossa. Afr J Paediatr Surg 2010; 7: 163-165.

9- Bhatt M, Joseph L, Ducharme FM, Dougherty G, McGillivray D: Prospective validation of the pediatric appendicitis score in a Canadian pediatric emergency department. Acad Emerg Med 2009; 16: 591-596.

10- Neilson IR, Laberge JM, Nguyen LT, Moir C, Doody D, Sonnino RE, Youssef S, Guttman FM: Appendicitis in children: Current therapeutic recommendations. J Pediatr Surg 1990; 25: 1113-1116.

11-Pearl RH, Hale DA, Molloy M, Schutt DC, Jaques DP: Pediatric appendectomy. $J$ Pediatr Surg 1995; 30: 173-178.

12-Korner H, Sondenaa K, Soreide JA, Andersen E, Nysted A, Lende TH, Kjellevold KH: Incidence of acute nonperforated and perforated appendicitis: Age-specific and sex-specific analysis. World J Surg 1997; 21: 313-317.

13-Stephen AE, Segev DL, Ryan DP, Mullins ME, Kim SH, Schnitzer JJ, Doody DP: The diagnosis of acute appendicitis in a pediatric population: To CT or not to CT. J PediatrSurg 2003; 38: 367-371.

14-Partrick DA, Janik JE, Janik JS, Bensard DD, Karrer FM: Increased CT scan utilization does not improve the diagnostic accuracy of appendicitis in children. $J$ Pediatr Surg 2003; 38: 659-662.

15-Flum DR, Koepsell T: The clinical and economic correlates of misdiagnosed appendicitis: Nationwide analysis. Arch Surg 2002; 137: 799-804.

16-Putnam TC, Gagliano N, Emmens RW: Appendicitis in children. Surg Gynecol Obstet 1990; 170: 527-532.
17-Emil S, Laberge JM, Mikhail P, Baican L, Flageole H, Nguyen L, Shaw K: Appendicitis in children:A ten-year update of therapeutic recommendations. J Pediatr Surg 2003; 38: 236-242.

18-Zielke A, Sitter H, Rampp T, Bohrer T, Rothmund M: Clinical decision-making, ultrasonography, and scores for evaluation of suspected acute appendicitis. World $J$ Surg 2001; 25:578-584.

19-Emil S, Mikhail P, Laberge JM, Flageole H, Nguyen LT, Shaw KS, Baican L, Oudjhane K: Clinical versus sonographic evaluation of acute appendicitis in children: A comparison of patient characteristics and outcomes. J Pediatr Surg 2001; 36: 780783.

20-Schuh S, Man C, Cheng A, Murphy A, Mohanta A, Moineddin R, Tomlinson G, Langer JC, Doria AS: Predictors of nondiagnostic ultrasound scanning in children with suspected appendicitis. JPediatr 2011; 158: 112-118.

21-Smink DS, Finkelstein JA, Garcia PeOa BM, Shannon MW, Taylor GA, Fishman SJ: Diagnosis of acute appendicitis in children using a clinical practice guideline. $J$ Pediatr Surg 2004; 39: 458-463.

22-Perez J, Barone JE, Wilbanks TO, Jorgensson D, Corvo PR: Liberal use of computed tomography scanning does not improve diagnostic accuracy in appendicitis. Am J Surg 2003; 185: 194197.

23-Peiia BM, Taylor GA, Fishman SJ, Mandl KD: Effect of an imaging protocol on clinical outcomes among pediatric patients with appendicitis. Pediatrics 2002; 110 : 1088-1093.

24-Grossman RG, Homer C, Goldman DA: Case 2: Establishing and running a clinical practice guideline program at Children's Hospital, Boston.In:Implementing Clinical Practice Guidelines. Margolis CZ, Cretin S (Editors); Chicago, IL, AHA Press (Publisher); 1999; p.151-175.

25-Cretin S: Evaluating and monitoring clinical practice guidelines. In: Implementing Clinical Practice Guidelines. Margolis CZ, Cretin S (Editors); Chicago, IL, AHA Press (Publisher); 1999; p.121-138. 
26-Cabana MD, Rand CS, Powe NR, Wu AW, Wilson MH, Abboud PA, Rubin HR:Why don't physicians follow clinical practice guidelines? A framework for improvement. JAMA 1999; 282: 1458-1465.

27-Grimshaw JM, Russell IT: Effect of clinical guidelines on medical practice: A systematic review of rigorous evaluations. Lancet1993;342: 1317-1322.

28-Wamer BW, Kulick RM, Stoops MM, Mehta S, Stephan M, Kotagal UR: An evidenced-based clinical pathway for acute appendicitis decreases hospital duration and cost. J Pediatr Surg 1998; 33: 13711375.

29-Firilas AM, Higginbotham PH, Johnson DD, Jackson RJ, Wagner CW, Smith SD: A new economic benchmark for surgical treatment of appendicitis. Am Surg 1999; 65: 769-773.

30- Choudhry S, Gorman B, Charboneau JW, Tradup DJ, Beck RJ, Kofler JM, Groth DS: Comparison of tissue harmonic imaging with conventional us in abdominal disease. Radio Graphics 2000; 20: 11271135.

31-Ward B, Baker AC, Humphrey VF: Nonlinear propagation applied to the improvement of resolution in diagnostic medical ultrasound.J Acoust Soc Am 1997; 101: 143-154.
32-Starritt HC, Duck FA, Hawkins AJ, Humphrey VF: The development of harmonic distortion in pulsed finiteamplitude ultrasound passing through liver. Phys Med Bioi 1986; 31: 1401-1409.

33-Starritt HC, Perkins MA, Duck FA, Humphrey VF: Evidence for ultrasonic finite-amplitude distortion in muscle using medical equipment. J Acoust Soc Am 1985; 77: 302-306.

34-Muir TG: Nonlinear effects in acoustic imaging. Acoust /mag 1980; 9: 93-109.

35-Ragavendra N, Chen H, Powers JE, Nilawat C, Robert JM, Carangi C, Laifer-Narin SL:Harmonic imaging of porcine intraovarian arteries using sonographic contrast medium: Initial findings. illtrasound Obstet Gynecol1997; 9: 266270.

36-Wu JY, Shung KK: Nonlinear energy exchange among harmonic modes and its applications to nonlinear imaging.J Acoust Soc Am 1990; 88: 2852-2858.

37-Siegel S: Nonparametric statistics for the behavioral sciences. New York, NY: McGraw-Hill, 1956: 68-75.

38-Shapiro RS, Wagreich J, Parsons RB, Stancato-Pasik A, Yeh HC, Lao R: Tissue harmonic imaging sonography: Evaluation of image quality compared with conventional sonography. AJR Am J Roentgenol1998; 171: 1203-1206. 